\title{
The Evaluation of PSA levels in Libyan Prostate Cancer Patients
}

\author{
Eman Elshahmi ${ }^{1}$, Fatma Emaetig ${ }^{2}$, Fauzia Elgaraboli ${ }^{3}$, Abubaker Abushnaf ${ }^{4}$, Omar Alqawi ${ }^{5}$ \\ ${ }^{1}$ Department of Zoology, Faculty of Science, Misurata University. \\ ${ }^{2}$ Department of Histopathology, National Cancer Institute, Misurata. \\ ${ }^{3}$ Department of Genetics, Faculty of Science, Misurata University. \\ ${ }^{4}$ Department of Urology, National Cancer Institute. \\ ${ }^{5}$ Genetic Engineering Centre, National Cancer Institute, Misurata.
}

*Corresponding Author: Omar Alqawi, Genetic Engineering Centre, National Cancer Institute, Misurata.

Received Date: September 28, 2021 | Accepted Date: December 24, 2021| Published Date: January 03, 2022

Citation: E Elshahmi, F Emaetig, F Elgaraboli, A Abushnaf, O Alqawi. (2022). The Evaluation of PSA levels in Libyan Prostate Cancer Patients; Clinical Oncology Research and Reports. 3(1); DOI: 10.31579/2693-4787/029

Copyright: (C) 2022 Omar Alqawi, This is an open-access article distributed under the terms of the Creative Commons Attribution License, which permits unrestricted use, distribution, and reproduction in any medium provided the original author and source are credited.

\begin{abstract}
Background: Prostate cancer is the second most frequent cancer and the fifth leading cause of cancer death in men with higher prevalence in the developed countries. The use of biomarkers for prostate cancer can improve the diagnosis of prostate cancer and clinical management of the patients. Prostate-specific antigen (PSA) is widely used to screen for prostate cancer and there is evidence that PSA testing reduces prostate cancer mortality.

Objective: In this report we have studied the relationship between the Gleason score, age and PSA levels of prostate adenocarcinoma tissues from Libyan patients to evaluate the levels of PSA in prostate cancer patients.

Materials and methods: The data was collected from medical files of 40 patients who underwent curative surgical prostatectomy or prostate true cut biopsy at National Cancer Institute (NCI)-Misurata, Libya during 2016 to 2018. The clinical and histopathological information included age, PSA levels, and Gleason score grade.

Results: Our data showed that PSA level was statistically significant correlation with Gleason score grade (p- value $=0.007,<0.05)$. The increased serum PSA level was associated with the progression of prostate cancer. However, we found no statistically significant correlation between PSA and the age of patients ( $\mathrm{p}$ - value $=0.435$ ).

Conclusion: Our data confirmed the association of high levels of PSA and the progress of prostate cancer.
\end{abstract}

Key words: prostate cancer, psa level, gleason score

\section{Introduction}

One of the most main health problems in men is prostate cancer. The rate of prostate cancer surges significantly after the age of 40 years, and around two-thirds of all prostate cancers happen in men of 65 years and older [1]. Prostate cancer is a unique heterogeneous disease. Prostate tumors can be indolent or very aggressive, often metastasizing to bone and other organs, thereby causing significant morbidity and mortality [2]. Prostate cancer has various features, so the prognosis following diagnosis is greatly variable. Some patients have inactive form of disease with no significant effect on mortality for 15 years. However, some patients have aggressive form of the disease as metastasis during 2 years [3]. PSA is a biomarker that is used for diagnosis and prognosis of prostate cancer. It is the most greatly noninvasive screening tool which causes enhanced detection at earlier stage and decreasing in the number of metastatic patients [4]. PSA is a kallekrein-like serine protease secreted by the epithelial cells of prostate. It functions to liquefy serum, promote sperm motility and dissolve cervical mucus [5]. It is present in normal prostatic secretions and is often raised in prostate cancer [6]. Serum PSA level is age and race adjusted, $6 \mathrm{ng} / \mathrm{ml}$ was defined as the upper normal limit [7]. Since high levels of PSA are found in more progressive stages, this biomarker has been used as a prognostic and staging tool [8]. Histopathological grading performed by Gleason scoring also used as an important prognostic indicator of prostate cancer [9]. The Gleason system is based on the degree of glandular differentiation where five patterns of growth are recognized and numbered in order of increasing aggressiveness. Because tumors may display variable histology, two patterns are recorded for each case: a primary pattern (Gleason 1-5) and a secondary pattern (Gleason 1-5). The Gleason score is the sum of the primary and secondary patterns and ranges from 2 to 10 [10] 
In this report, we studied the correlation between PSA levels and Gleason scores of patients to evaluate the significant of PSA in detection of advanced prostate tumors, and to improve the management of the disease.

\section{Materials and Methods}

The data was collected from medical files of 40 patients diagnosed with prostate cancer and underwent curative surgical prostatectomy or prostate true cut biopsy at National Cancer Institute (NCI)-Misurata, Libya during 2016 to 2018. The clinical and histopathological information included age, PSA levels, and Gleason score of the tumor which obtained from the archive of Histopathology Department. The study was approved by the ethical committee of the NCI-Misurata, and the consents were signed by the patients.

The data was analyzed using SPSS version 20.0 statistical software. The results were evaluated for significance with chi-squared test. $\mathrm{P}$ value < 0.05 was considered to indicate a statistically significant difference.

\section{Results}

The studied cases of prostate cancer were aged between 60 and 90 years (average 76.3 years). The most recurrence rate was found in 70 years and over $33 / 40(82.5 \%)$ which included $18 / 33(54.5 \%)$ under the age of 80 years, and $15 / 33(45.4 \%)$ under the age of 91 years. Patients aged under 70 years were $7 / 40(17.5 \%)$. Concerning the Gleason score of the prostate tissues, the study showed that $15 / 40(37.5 \%)$ were in score $4(2+2), 11 / 40$ $(27.5 \%)$ in score $6(3+3), 2 / 40(5 \%)$ in score $7(3+4), 7 / 40(17.5 \%)$ in score $8(4+4), 1 / 40(2.5 \%)$ was in score $9(4+5)$, and $4 / 40(10 \%)$ were in score $10(5+5)$. The grading of the examined tissues revealed that $26 / 40$ $(65 \%)$ were in well differentiation, $2 / 40(5 \%)$ in moderate differentiation and $12 / 40(30 \%)$ in poor differentiation (Figure-1). Regarding the levels of serum PSA of prostate cancer patients, we found that $2 / 40(5 \%)$ were under the level of $10 \mathrm{ng} / \mathrm{dl}$ while $38 / 40(95 \%)$ were higher than $10 \mathrm{ng} / \mathrm{dl}$, which distributed as; $13 / 38(34 \%)<40 \mathrm{ng} / \mathrm{dl}, 17 / 38(44.7 \%)<100 \mathrm{ng} / \mathrm{dl}$, and $8 / 38(21.1 \%)>100 \mathrm{ng} / \mathrm{dl}$. (Figure-2).

The statistical analysis showed that PSA level was statistically significant correlation with Gleason score grade $(\mathrm{p}$ - value $=0.007$,$) (table1). This$ indicates the increase of serum PSA levels in advanced progression of prostate cancer cases. However, we found no statistical significance between PSA level of prostate cancer patients and the ages of patients ( $\mathrm{p}$ value $=0.435$ ). Our results showed a trend for a higher PSA levels in ages $>70$ years, particularly at the ages between 70 and 79 years (table2).

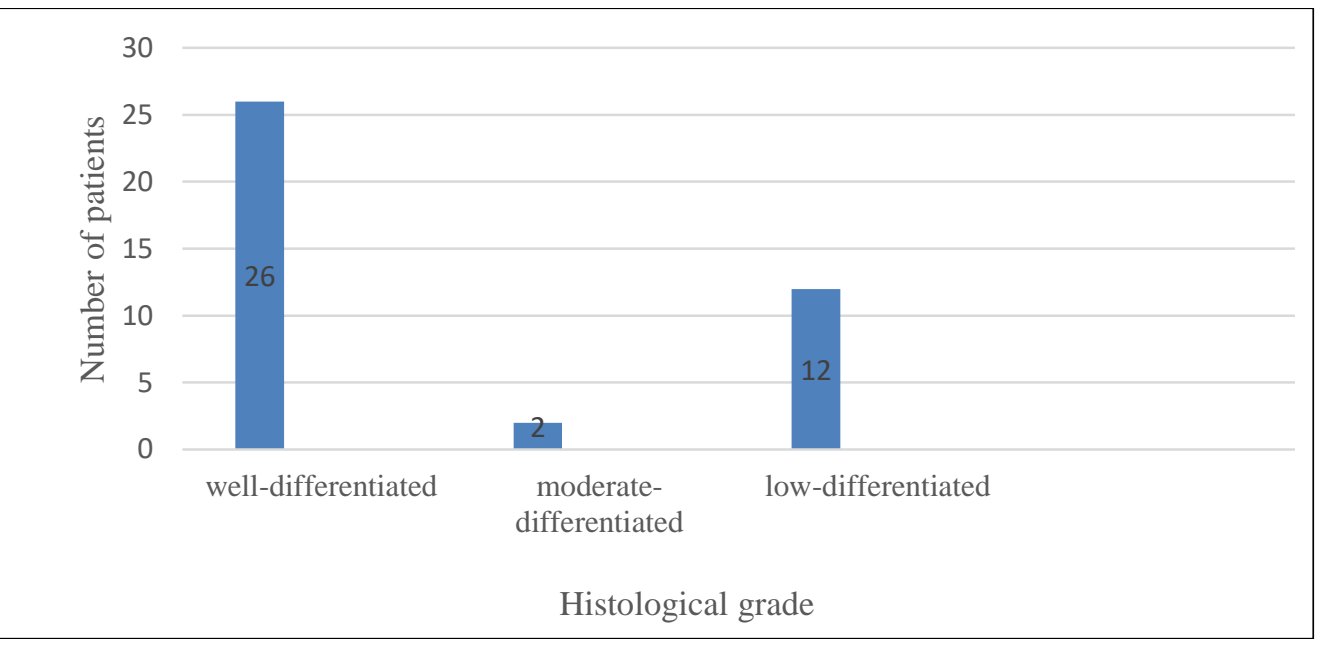

Figure 1: The Gleason grade of the studied prostate adenocarcinoma tissues

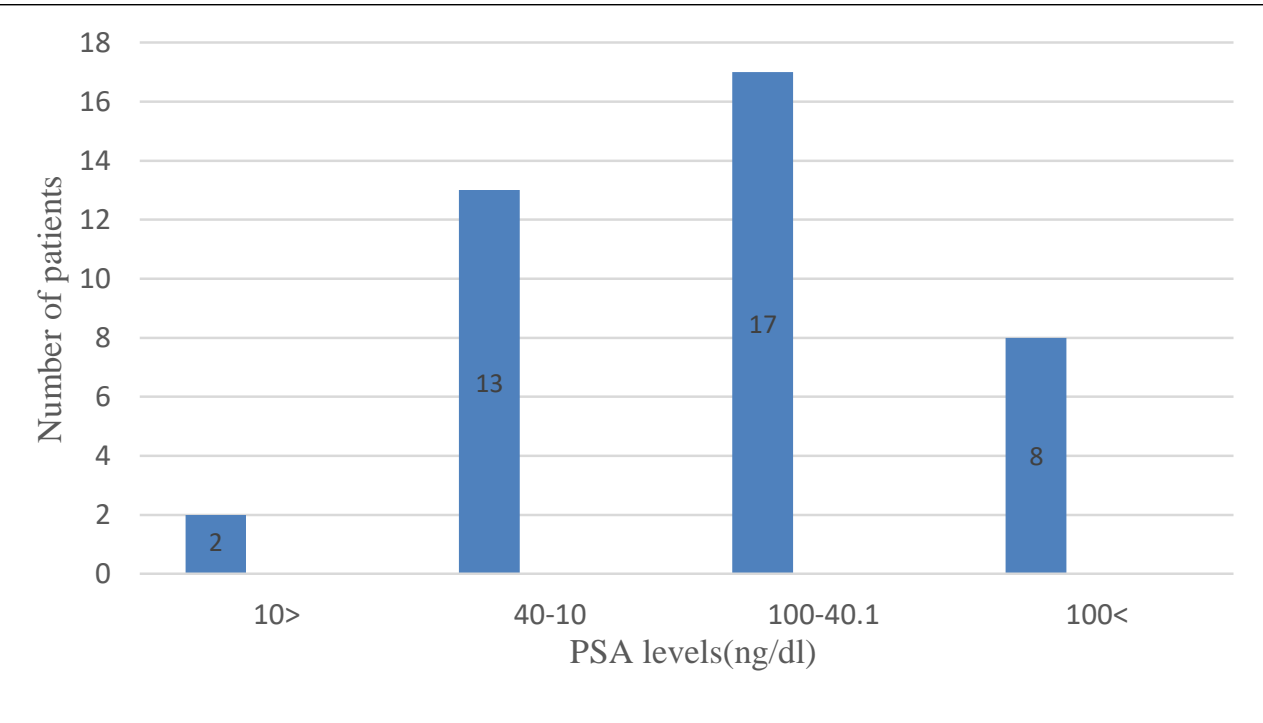

Figure 2: The distribution of PSA level among prostate adenocarcinoma patients. 


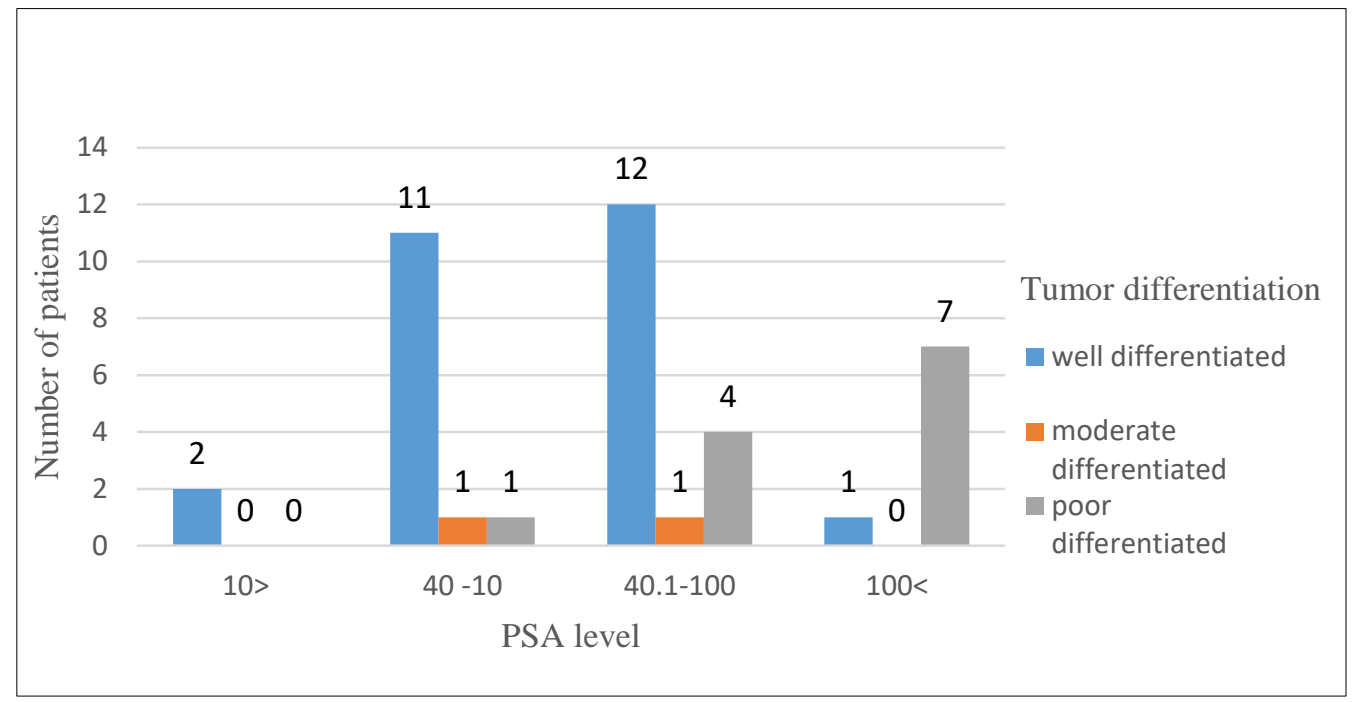

Figure 3: The frequency of tumor grading among prostate adenocarcinoma patients with PSA level.

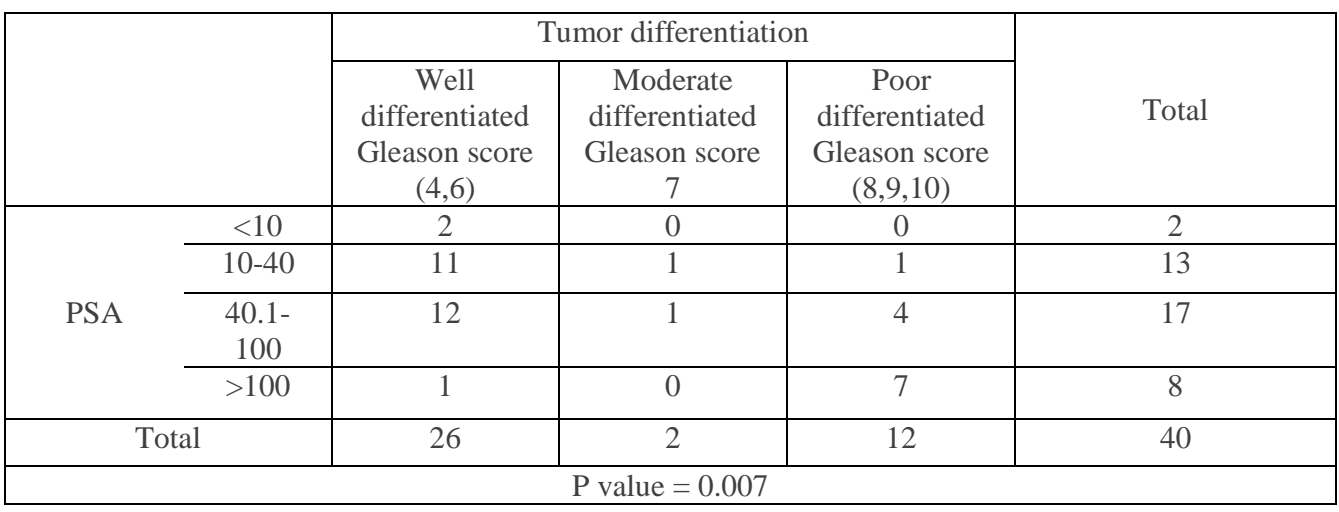

Table 1: The correlation of PSA levels with tumor differentiation

\begin{tabular}{|c|c|c|c|c|c|}
\hline & & \multicolumn{3}{|c|}{ Age factor(years) } & \multirow{2}{*}{ Total } \\
\hline & & $60--69$ & $70-79$ & 80--- & \\
\hline \multirow{4}{*}{ PSA } & $<10$ & 1 & 0 & 1 & 2 \\
\hline & $10-40$ & 3 & 4 & 6 & 13 \\
\hline & $40.1-100$ & 1 & 10 & 6 & 17 \\
\hline & $>100$ & 2 & 4 & 2 & 8 \\
\hline \multicolumn{2}{|l|}{ Total } & 7 & 18 & 15 & 40 \\
\hline \multicolumn{6}{|c|}{$\mathrm{P}$ value $=0.453$} \\
\hline
\end{tabular}

Table 2: The correlation of PSA levels with the age of patients

\section{Discussion}

Prostate cancer has a slow growth rate and most patients have slowly progressive disease and should be treated conservatively. Unfortunately, $10 \%$ of patients will progress to metastatic prostate cancer which is a high fatal malignancy, causing large number of deaths annually. Patients with metastatic prostate cancer should have aggressive treatment at the initial sign of the disease [11]. The surviving rate for patients diagnosed with metastatic prostate cancer remains humble, and more screening strategies are necessary to reduce the possible increase in prostate cancer mortality [12]. The discovery of prostate-specific antigen (PSA) and the following approval of PSA screening have made it possible to diagnose the disease early. After the introduction of PSA testing, the rate of prostate cancer diagnosis increased, and its associated mortality decreased [13]. High levels of PSA were found in progressive stages of prostate cancer. As a result, PSA has been used as a staging and prognostic biomarker. Our data supported the notion that PSA increases more in prostate cancer tissues with higher Gleason scores (Figure 3). Kumari et al., (2020) [14] at their prospective study on 100 prostatic tissues including 29 adenocarcinoma tissues, concluded that PSA is a sensitive marker for the diagnosis of prostate cancer with a positive correlation between serum PSA level and Gleason's grading. The mean serum PSA level of moderately and poorly differentiated carcinoma was $30.15 \mathrm{ng} / \mathrm{dl}$ and $325.3 \mathrm{ng} / \mathrm{dl}$ respectively. Albasri et al., (2014) [15] and Zivkovic et al., (2004) [16] also had a similar observation. A study carried by Hayashi et al., (2017) [17] on 966 men with suspicion of prostate cancer, 553 of them were positive for prostate cancer including 422 with high Gleason score. The data showed a positive correlation between PSA and Gleason score $(p<0.01)$. The 
mean serum PSA level of low Gleason score cancer and high Gleason score cancer was $7.53 \mathrm{ng} / \mathrm{ml}$ and $13.29 \mathrm{ng} / \mathrm{ml}$ respectively. Nnabugwu et al., (2016) [18] at their study on black men found no significant association between PSA and Gleason score $(p=0.35)$. This is similar to the findings of Izumi et al. (2015) [19]. However, due to its increased rates in other diseases of prostate; the use of PSA as a diagnostic tool has become controversial [20]. The United States Preventive Services Task Force impelled much argument over PSA-based screening in 2012 by recommending against this approach. The 2017 guidelines issued by USPSTF recommend PSA-based screening for men between the ages of 55 and 69 years [21]. The European Randomized Study of Screening for Prostate Cancer (ERSPC) conducted in several centers proposed that men could be undergo three PSA tests between the ages of 45 and 60 years as a strategy of early detection of prostate cancer [5]. Some studies found that metastatic prostate cancer incidence rates increased from 2012 to

\section{References}

1. Bashir M. N. (2015). Epidemiology of prostate cancer. Asian Pacific journal of cancer prevention. 16(13), 5137-5141.

2. Loberg R. D, Logothetis C. J, Keller E. T, \& Pienta K. J. (2005). Pathogenesis and treatment of prostate cancer bone metastases: targeting the lethal phenotype. Journal of clinical oncology. 23(32), 8232-8241.

3. Siddiqui E, Mumtaz F. H, \& Gelister J. (2004). Understanding prostate cancer. The journal of the Royal Society for the Promotion of Health, 124(5), 219-221.

4. Cary K. C, \& Cooperberg M. R. (2013). Biomarkers in prostate cancer surveillance and screening: past, present, and future. Therapeutic advances in urology, 5(6), 318-329.

5. Pezaro C, Woo H. H, \& Davis I. D. (2014). Prostate cancer: measuring PSA. Internal medicine journal. 44(5), 433-440.

6. Sarwar S, Adil M. A. M, Nyamath P, \& Ishaq M. (2017). Biomarkers of prostatic cancer: an attempt to categorize patients into prostatic carcinoma, benign prostatic hyperplasia, or prostatitis based on serum prostate specific antigen, prostatic acid phosphatase, calcium, and phosphorus. Prostate Cancer.

7. Esfahani M, Ataei N, \& Panjehpour M. (2015). Biomarkers for evaluation of prostate cancer prognosis. Asian Pacific Journal of Cancer Prevention, 16(7), 2601-2611.

8. Shariat S. F, Canto E. I, Kattan M. W, \& Slawin K. M. (2004). Beyond prostate-specific antigen: new serologic biomarkers for improved diagnosis and management of prostate cancer. Reviews in urology. 6(2), 58.

9. Epstein J. I. (2010). An update of the Gleason grading system. The Journal of urology. 183(2), 433-440.

10. Michalski J, Pisansky T, Lawton C, \& Potters L. (2016). Prostate Cancer. In Clinical Radiation Oncology. (4th edition), (pp. 1038-1095.e1018).

11. Rice M. A, \& Stoyanova T. (2019). Biomarkers for diagnosis and prognosis of prostate cancer. Prostatectomy.

12. Downer M. K, Stampfer M. J \& Cooperberg, M. R. (2017). Declining incidence rates of prostate cancer in the United States: is this good news or not? JAMA oncology. 3(12), 16231624.
2014 after the mentioned USPSTF recommendations [22]. Our results have showed the significant role of PSA screening in diagnosis and prognosis of prostate cancer.

\section{Conclusion}

This study has found a significant increase in PSA levels in prostate cancer patients with advanced Gleason scores. Our results supported the significant role of PSA as a prognostic tool. PSA test remains the most greatly noninvasive screening tool enhanced detection at earlier stage and reducing the number of metastatic cases.

Acknowledgment: We would like to thank the team of Histopathology Department at NCI-Misurata for their help and support. Our gratitude is extended to the administration of NCI-Misurata for the support during the study.

13. Hatakeyama S, Yoneyama $\mathrm{T}$, Tobisawa $\mathrm{Y} \&$ Ohyama $\mathrm{C}$. (2017). Recent progress and perspectives on prostate cancer biomarkers. International journal of clinical oncology. 22(2), 214-221.

14. Kumari K, Sharma N, Asotra, S, Sharad S, Sharma R \& Thakur R. (2020). Correlation between Gleason score of adenocarcinoma prostate and serum PSA levels in the western Himalayan region of India. Indian Journal of Pathology and Oncology 7(2). 223-227.

15. Albasri A, El-Siddig A, Hussainy A, Mahrous M, Alhosaini A. A, \& Alhujaily A. (2014). Histopathologic characterization of prostate diseases in Madinah, Saudi Arabia. Asian Pacific Journal of Cancer Prevention. 15(10), 4175-4179.

16. Živković S. (2004). Correlation between prostate-specific antigen and histopathological difference of prostate carcinoma. Archive of Oncology. 12(3), 148-151.

17. Hayashi T, Fujita K, Tanigawa G, Kawashima A, Nagahara A, Ujike T. \& Nonomura N. (2017). Serum monocyte fraction of white blood cells is increased in patients with high Gleason score prostate cancer. Oncotarget. 8(21), 35255.

18. Nnabugwu I. I, Udeh E. I, Ugwumba F. O, \& Ozoemena F. O. (2016). Predicting Gleason score using the initial serum total prostate-specific antigen in Black men with symptomatic prostate adenocarcinoma in Nigeria. Clinical interventions in aging. 11, 961.

19. Izumi K, Ikeda H, Maolake, Machioka, Nohara T, Narimoto K \& Namiki M. (2015). The relationship between prostatespecific antigen and TNM classification or Gleason score in prostate cancer patients with low prostate-specific antigen levels. The Prostate. 75(10), 1034-1042.

20. O'Shaughnessy M, Konety B, \& Warlick C. (2010). Prostate cancer screening: issues and controversies. Minnesota medicine. 93(8), 39-44.

21. Bibbins-Domingo K, Grossman D. C, \& Curry S. J. (2017). The US Preventive Services Task Force 2017 draft recommendation statement on screening for prostate cancer: an invitation to review and comment. Jama. 317(19), 1949-1950.

22. Kelly S. P, Anderson W. F, Rosenberg P. S \& Cook M. B. (2018). Past, current, and future incidence rates and burden of metastatic prostate cancer in the United States. European urology focus. 4(1), 121-127. 
This work is licensed under Creative Commons Attribution 4.0 License

To Submit Your Article Click Here:

Submit Manuscript

DOI: $10.31579 / 2693-4787 / 029$
Ready to submit your research? Choose Auctores and benefit from:

* fast, convenient online submission

* rigorous peer review by experienced research in your field

* rapid publication on acceptance

* authors retain copyrights

* unique DOI for all articles

* immediate, unrestricted online access

At Auctores, research is always in progress.

Learn https://auctoresonline.org/journals/clinical-oncology-researchand-reports 